\title{
Cerebellar Direct Current Stimulation Enhances On-Line Motor Skill Acquisition through an Effect on Accuracy
}

\author{
Gabriela Cantarero, ${ }^{1}$ Danny Spampinato, ${ }^{1}$ Janine Reis, ${ }^{2}$ Loni Ajagbe, ${ }^{1}$ Tziporah Thompson, ${ }^{1}$ Kopal Kulkarni, ${ }^{1}$ \\ and Pablo Celnik ${ }^{1,3}$ \\ ${ }^{1}$ Department of Physical Medicine and Rehabilitation, Johns Hopkins Medical Institution, Baltimore, Maryland 21205, 2Department of Neurology, Albert- \\ Ludwigs-University Freiburg, 79106 Freiburg, Germany, and ${ }^{3}$ Department of Neurology, Johns Hopkins Medical Institution, Baltimore, Maryland 21205
}

\begin{abstract}
The cerebellum is involved in the update of motor commands during error-dependent learning. Transcranial direct current stimulation (tDCS), a form of noninvasive brain stimulation, has been shown to increase cerebellar excitability and improve learning in motor adaptation tasks. Although cerebellar involvement has been clearly demonstrated in adaptation paradigms, a type of task that heavily relies on error-dependent motor learning mechanisms, its role during motor skill learning, a behavior that likely involves errordependent as well as reinforcement and strategic mechanisms, is not completely understood. Here, in humans, we delivered cerebellar tDCS to modulate its activity during novel motor skill training over the course of $3 \mathrm{~d}$ and assessed gains during training (on-line effects), between days (off-line effects), and overall improvement. We found that excitatory anodal tDCS applied over the cerebellum increased skill learning relative to sham and cathodal tDCS specifically by increasing on-line rather than off-line learning. Moreover, the larger skill improvement in the anodal group was predominantly mediated by reductions in error rate rather than changes in movement time. These results have important implications for using cerebellar tDCS as an intervention to speed up motor skill acquisition and to improve motor skill accuracy, as well as to further our understanding of cerebellar function.
\end{abstract}

Key words: cerebellum; skill learning; tDCS

\section{Introduction}

Learning motor skills is essential in contemporary daily living. Our ability to learn new motor patterns depends on multiple behavioral and neural mechanisms. For instance, plastic changes have been described in the primary motor cortex (M1; Karni et al., 1995; Cantarero et al., 2013b) and its interconnected regions (i.e., the cerebellum; Black et al., 1990; Anderson et al., 1996; Kleim et al., 2002).

The process of motor learning has been dissected into distinct stages: acquisition, evidenced by performance improvements during practice (on-line changes), and retention, defined by performance after a break period (off-line changes). Recent studies have suggested that M1 and the cerebellum play different roles in the acquisition and retention of motor tasks (Reis et al., 2009; Galea et al., 2011). The cerebellum has been implicated in the updating of motor commands during error-dependent learning (Schlerf et al., 2012), playing a prominent role during acquisition of motor adaptation tasks (Smith and Shadmehr, 2005; Donchin

\footnotetext{
Received July 15, 2014; revised Dec. 19, 2014; accepted Jan. 8, 2015.

Author contributions: J.R. and P.C. designed research; L.A. and K.K. performed research; G.C., D.S., and T.T. analyzed data; G.C. and P.C. wrote the paper.

This work was supported by the National Institute of Child Health and Human Development, the National Institutes of Health (R01HD053793 and R01HD073147), the Brain Science Institute of Johns Hopkins University, and the National Institute of Neurological Disorders and Stroke (1F31NS073386-01A1).

The authors declare no competing financial interests.

Correspondence should be addressed to Pablo Celnik, Department of Physical Medicine and Rehabilitation, Johns Hopkins Medical Institution, 707 N. Broadway, Baltimore, MD 21231. E-mail: pcelnik@jhmi.edu.

DOI:10.1523/JNEUROSCI.2885-14.2015

Copyright $\odot 2015$ the authors $\quad 0270-6474 / 15 / 353285-06 \$ 15.00 / 0$
}

et al., 2012). In contrast, $M 1$ is involved in the retention of motor learning, including adaptation and skill tasks (Muellbacher et al., 2002; Robertson et al., 2004; Richardson et al., 2006; Cantarero et al., 2013a).

Studies in healthy individuals (Diedrichsen et al., 2005; Donchin et al., 2012) and cerebellar degeneration patients (Martin et al., 1996; Smith and Shadmehr, 2005) demonstrated the cerebellar role during adaptation. This feedforward form of error-dependent learning has a timescale of minutes to hours where predictions about motor outcome are compared with actual motor outcomes (Bastian, 2008). These investigations, however, do not provide information about cerebellar involvement in motor skill tasks. Learning skills entails bringing performance to a new level by acquiring new knowledge (Krakauer and Mazzoni, 2011). This process occurs on a timescale of hours to days (Dayan and Cohen, 2011), has been operationalized as shifts in the speed-accuracy tradeoff function, and likely engages error-based learning in addition to other mechanisms of motor learning, such as strategic learning, reinforcement (driven by reward), and use-dependent learning (learning that favors repetition of prior movements).

Transcranial direct current stimulation (tDCS), known to modulate M1 cortical plasticity through NMDA, GABA, BDNF, and calcium-dependent mechanisms (Liebetanz et al., 2002; Stagg et al., 2009; Fritsch et al., 2010), can also induce changes in cerebellar excitability. Namely, anodal tDCS increases cerebellar excitability, whereas cathodal tDCS decreases it (Galea et al., 2009). Importantly, cerebellar anodal tDCS improves acquisition in reaching (Galea et al., 2011) and locomotor adaptation para- 
A

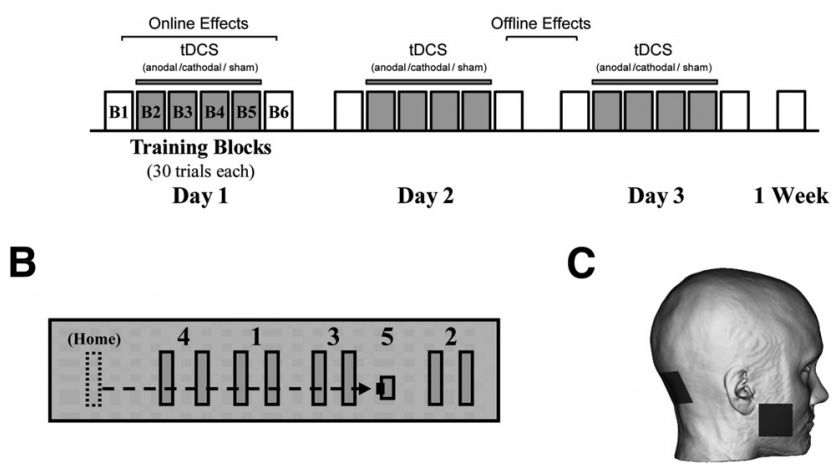

Figure 1. Experimental design. $A$, Subjects participated in $3 \mathrm{~d}$ of motor training, practicing six blocks of 30 trials each day, followed by a 1 week post-test of 30 trials. Two milliamperes of anodal, cathodal, or sham tDCS was applied over the right cerebellar cortex during Blocks $2-5$ of training (gray blocks). On-line effects were calculated as the sum of the difference between Blocks 1 and 6 for each day. Off-line gains were estimated as the sum of differences between the first block of day 2 and 3 minus the last block of day 1 and 2 respectively. $\boldsymbol{B}$, Participants used a pinch force transducer to control the cursor on a computer screen. Subjects were instructed to complete the sequence HOME-1-HOME-2-HOME-3-HOME-4-HOME-5 by alternating the pinch force exerted onto the transducer. $\boldsymbol{C}$, Target region for cerebellar stimulation. One electrode was centered over the right cerebellar cortex $(3 \mathrm{~cm}$ lateral to the inion) and the other electrode was placed on the right buccinator muscle.

digms (Jayaram et al., 2012), as shown by rapid decreases in the number of movements required to correct errors.

Here we investigated three issues: (1) the impact cerebellar tDCS (ctDCS) has on motor skill learning, (2) the impact ctDCS has on the stage of learning affected (on-line vs off-line), and (3) the effects of ctDCS on specific behavioral components (accuracy vs speed). Since ctDCS enhances adaptation and error-based learning mechanisms are likely present during early stages of skill learning, we hypothesized that anodal ctDCS would improve motor skill through the facilitation of on-line acquisition. Furthermore, we predicted that this effect would be predominantly mediated by reduction of errors.

\section{Materials and Methods}

We recruited 33 healthy right-handed individuals ( 13 males and 20 females) with no history of neurological or psychiatric conditions. All gave written informed consent to participate in this study, which was approved by the Johns Hopkins Institutional Review Board and in accordance to the Declaration of Helsinki.

Experimental procedure. All subjects trained at the same time of day on a visuomotor skill task over the course of 3 consecutive days. Each day subjects trained 180 trials (six blocks of 30 trials). In a double-blind fashion, participants received $2 \mathrm{~mA}\left(80 \mu \mathrm{A} / \mathrm{cm}^{2}\right)$ of either anodal $(n=$ 11 ; mean age, $23.18 \pm 1.20$ years; four male; seven female), cathodal $(n=$ 11 ; mean age, $27.90 \pm 2.56$ years; five male; six female), or sham ( $n=11$; mean age, $23.82 \pm 1.36$ years; four male; seven female) tDCS applied over the ipsilateral cerebellum to the training hand. No subjects reported any knowledge or awareness of having received sham versus real stimulation. Training Blocks 1 and 6 were always performed without stimulation (Fig. $1 A$ ). Long-term retention of skill performance (30 trials of sequential visual isometric pinch task) was tested 1 week after training.

tDCS. tDCS was delivered through two $25 \mathrm{~cm}^{2}$ sponge electrodes soaked in a saline solution. We implemented a bipolar electrode montage with one electrode centered over the right cerebellar cortex, $3 \mathrm{~cm}$ lateral to the inion (Galea and Celnik, 2009), and the other electrode placed on the right buccinator muscle (Fig. $1 C$ ). In this manner, subjects received anodal, cathodal, or sham tDCS over the cerebellum during Blocks 2-5 of training using a Phoresor II Auto (model PM850, Iomed), which lasted $\sim 20 \mathrm{~min}$. The intensity of stimulation was ramped up to $2 \mathrm{~mA}$ before beginning training on Block 2 and ramped down to 0 after completion of
Block 5 (and before beginning Block 6). In the sham session, anodal tDCS was applied for $30 \mathrm{~s}$ and then shut off. This form of stimulation and montage is known to affect cerebellar-M1 connectivity (Galea and Celnik, 2009) as well as adaptation-learning paradigms (Galea et al., 2011; Jayaram et al., 2011, 2012; Schlerf et al., 2012). In addition, it has been shown in modeling studies that this montage is effective at targeting one cerebellar hemisphere with little diffusion to other brain regions (Rampersad et al., 2014). Although the exact underlying mechanisms of this stimulation in the cerebellum are unknown, in the motor cortex this form of stimulation has been shown to increase cortical excitability through NMDA receptors, GABA, BDNF, and calcium-dependent mechanisms (Islam et al., 1995; Liebetanz et al., 2002; Nitsche et al., 2003a; Stagg et al., 2009; Fritsch et al., 2010) and induce LTP in mice slice preparations (Fritsch et al., 2010).

Skill task: sequential visual isometric pinch task. The generalities of the skill task have been previously described (Reis et al., 2009; Cantarero et al., 2013a). Subjects held an isometric force transducer between the thumb and index finger of the right hand and used the transducer to control the movement of an on-screen cursor. A logarithmic transduction of pinch force onto cursor movement was imposed to make the task more difficult and prolong learning. The force values set for maximum rightward movement was identical to that identified by Reis et al. (2009). Participants were instructed to navigate the cursor between a HOME position and five gates (the sequence was HOME-1-HOME-2-HOME3-HOME-4-HOME-5) by alternating the pinch force exerted onto the transducer (Fig. 1B). A STOP signal appeared once subjects had reached and held their cursor over Gate 5, cuing the end of the trial. Subjects were instructed to perform the task as quickly and accurately as possible. Other than a repetition of the task instructions, no other verbal feedback was provided.

Movement time per trial was defined as the time from movement onset to reaching Gate 5 . Error rate was the proportion of trials with $\geq 1$ overshooting or undershooting movement per block, where each block was the average of 30 consecutive trials. In addition, we also quantified changes in accuracy in terms of total sum of errors across blocks and force distance error from the target across blocks. The total sum of errors is the total number of missed targets per trial (i.e., $\leq 4$ errors per trial if all targets are missed). The force distance error from target is defined as the absolute value of the distance between the peak pinch force applied by the subject and the correct pinch force necessary to correctly navigate the cursor inside the target. For example, larger values are indicative of missing the target by a larger distance.

To quantify motor learning, we determined changes in the speedaccuracy trade-off function (SAF). The proposed estimate of changes in the SAF is the skill measure, $a$, expressed as follows:

$$
a=\frac{1-\text { error rate }}{\text { error rate }\left(\ln (\text { movement time })^{b}\right)}
$$

where error rate and movement time are averages over 30 trials, and the value of $b$ is 5.424 (Reis et al., 2009).

To measure performance of the motor skill, we calculated total online, total off-line, and total gains, defined as follows:

sum on-line effects

$$
\begin{aligned}
& =\left(\text { skill measure }_{\text {Day1, last epoch }}-\text { skill measure }_{\text {Day1, first epoch }}\right) \\
& +\left(\text { skill measure }_{\text {Day2, last epoch }}-\text { skill measure }_{\text {Day2, first epoch }}\right) \\
& \quad+\left(\text { skill measure }_{\text {Day3, last epoch }}-\text { skill measure }_{\text {Day3, first epoch }}\right) ;
\end{aligned}
$$

sum off-line effects

$$
\begin{aligned}
& =\left(\text { skill measure }_{\text {Day2, first epoch }}-\text { skill measure }_{\text {Day1, last epoch }}\right) \\
& \quad+\left(\text { skill measure }_{\text {Day3, first epoch }}-\text { skill measure }_{\text {Day2, last epoch }}\right) ;
\end{aligned}
$$

total gains $=$ skill measure Day3, last epoch - skill measure $_{\text {Day1, first epoch. }}$. 
A

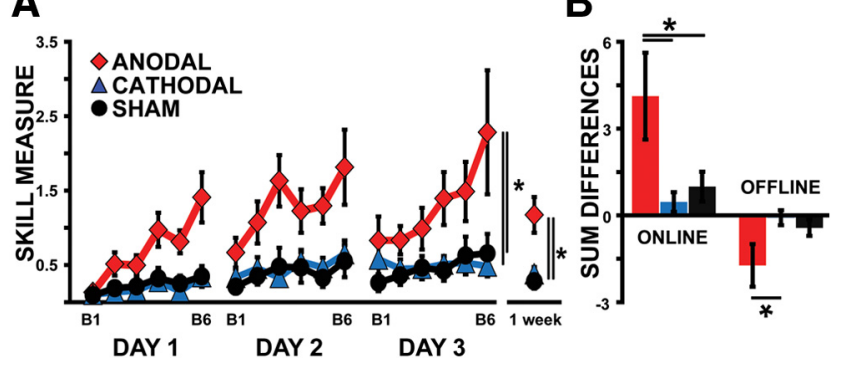

Figure 2. Skill measure. Red diamonds are the average performances of the Anodal group. Blue triangles represent the Cathodal group. Black circles denote the Sham group. $\boldsymbol{A}, \boldsymbol{y}$-axis represents the skill measure and $x$-axis depicts blocks of training across days. Note that although all subjects started with similar skill level, those who trained with anodal tDCS outperformed both the Cathodal and Sham stimulation groups. $\boldsymbol{B}$, The bar graph shows groups averages of the skill measure for the sum of on-line and off-line changes. Subjects with anodal stimulation showed larger improvements in on-line changes and larger losses in off-line changes compared with Cathodal and Sham groups. Data are means \pm SEM. ${ }^{*} p \leq 0.05$.

Data analysis. Differences in performance of the skill measure were compared using a polynomial nested repeated measure of ANOVA $\left(\right.$ ANOVA $_{\mathrm{RM}}$ ) with GROUP (Anodal, Cathodal, Sham) as the between factor and DAY (D1, D2, D3) and BLOCK (B1, B2, B3, B4, B5, B6) as within factors. Differences in on-line and off-line effects were compared using a one-way ANOVA. Least significant difference post hoc analysis corrected for multiple comparisons was done when appropriate with two-tailed $t$ tests. Identical polynomial nested $\mathrm{ANOVA}_{\mathrm{RM}}$ and one-way ANOVA statistical measures were done for error rate (proportion of trials with $\geq 1$ overshooting or undershooting movement per block) and movement time (time in seconds from initial movement to reaching Gate 5).

\section{Results}

Cerebellar anodal tDCS significantly improved skill learning relative to sham and cathodal tDCS

To assess learning, we compared group differences in the skill measure across days and blocks in the Anodal, Cathodal, and Sham groups. We found a significant effect on the skill measure for DAY $\left(F_{(2,60)}=15.96, p<0.01\right)$, BLOCK $\left(F_{(5,150)}=7.82, p<\right.$ $0.01)$, and BLOCK $\times$ GROUP interaction $\left(F_{(10,150)}=2.80, p<\right.$ 0.01 ), indicating that all groups experienced significant improvement in total skill learning over the course of training. Of note, we also found a significant effect for $\operatorname{GROUP}\left(F_{(2,30)}=7.38, p<\right.$ $0.01)$ where the Anodal tDCS group exhibited significantly greater overall skill learning compared with both the Sham $(p<$ 0.01 ) and Cathodal tDCS $(p<0.01)$ groups (Fig. $2 A)$. In contrast, subjects in the Cathodal group did not show a significant difference in total learning compared with subjects in the Sham group ( $p=0.93$ ). Additionally, there was a significant effect for better long-term retention in the Anodal group after a 1 week follow-up $\left(F_{(2,32)}=9.39, p<0.01\right)$ where the Anodal tDCS group had better overall performance compared with both the Sham $(p<0.01)$ and Cathodal tDCS $(p<0.01)$ groups (Fig. $2 A)$. Importantly, these findings were present in the absence of significant differences across groups in the first block of training for $\operatorname{skill}\left(F_{(2,32)}=0.15, p=0.86\right)$, error $\left(F_{(2,32)}=0.58, p=0.57\right)$, and movement time $\left(F_{(2,32)}=0.66, p=0.94\right)$. Thus, these results indicate that anodal tDCS led to overall better performance in the sequential visual isometric pinch task.

\section{Cerebellar anodal tDCS enhanced acquisition through on-line effects}

After establishing a difference in total learning between the Anodal, Sham, and Cathodal groups, we next determined the rela- tive impact of anodal tDCS on on-line (within-day) and off-line (between-day) effects. We found a significant difference in online effects between the three groups $\left(F_{(2,31)}=3.75, p=0.04\right)$, with anodal-stimulated subjects showing larger gains over the course of training compared with both Sham and Cathodal groups $(p=0.04, p=0.02$ respectively; Fig. $2 B)$. There was also a significant difference for off-line changes $\left(F_{(2,32)}=3.29, p=\right.$ 0.05 ; Fig. $2 B$ ) where the anodal tDCS subjects had larger negative off-line effects compared with cathodal tDCS subjects $(p=0.02)$ and a strong trend toward larger negative off-line effects relative to sham subjects $(p=0.06)$. To understand whether the off-line loss was proportional to the level of performance achieved at the end of each session, we calculated the percentage decrement in off-line changes for each group. We found no significant differences in the mean percentage loss across days $\left(F_{(2,32)}=0.99, p=\right.$ $0.38)$. This indicates that although the Anodal group has larger off-line changes in absolute terms, the relative percentage decrement is not different across groups. In addition, when comparing total gains across groups, the Anodal tDCS group $\left(F_{(2,31)}=3.55\right.$, $p=0.04$ ) exhibited significantly greater overall learning compared with both the Sham $(p=0.04)$ and Cathodal tDCS $(p=$ 0.02 ) groups. Altogether these results showed that cerebellar anodal tDCS effects on total learning are mediated by facilitation of on-line acquisition during motor skill learning.

\section{Cerebellar anodal tDCS led to larger reductions in errors during training}

To understand the component of skill-learning ctDCS affected the most, we dissected the skill measure back into its individual components (error rate and movement time).

Although all groups started with similar error level, we found a significant effect in the error rate for $\operatorname{BLOCK}\left(F_{(5,150)}=7.29, p\right.$ $<0.01)$, GROUP $\left(F_{(2,30)}=6.66, p<0.01\right)$, BLOCK $\times$ GROUP interaction $\left(F_{(10,150)}=3.10, p<0.01\right)$ and DAY $\times$ BLOCK $\times$ GROUP interaction $\left(F_{(20,300)}=2.19, p<0.01\right)$. Anodal subjects produced overall fewer errors than subjects in the Sham $(p<$ $0.01)$ and Cathodal groups $(p=0.03$; Fig. $3 A)$. There was no significant difference between the Sham and Cathodal groups $(p=0.19)$. Also, there was a significant difference in the 1 week follow-up assessment $\left(F_{(2,32)}=7.18, p<0.01\right)$ with anodal subjects overall maintaining better accuracy than subjects in the Sham $(p<0.01)$ and Cathodal groups $(p=0.01$; Fig. $3 A)$.

In addition, we looked at two additional measures to quantify accuracy: total sum of errors across blocks (i.e., the sum of the total number of missed targets per trial) and the force distance error from the targets (i.e., the distance between the peak pinch force applied by the subject and the correct pinch force necessary to correctly navigate the cursor inside each target). Similar to error rate, we found for the total sum of errors a significant effect for DAY $\left(F_{(2,60)}=3.29, p=0.04\right), \operatorname{BLOCK}\left(F_{(5,150)}=4.93, p<\right.$ $0.01), \operatorname{GROUP}\left(F_{(2,30)}=6.66, p<0.01\right), \mathrm{BLOCK} \times$ GROUP interaction $\left(F_{(10,150)}=1.99, p=0.04\right)$, and DAY $\times$ BLOCK $\times$ GROUP interaction $\left(F_{(20,300)}=1.66, p=0.04\right)$. Anodal subjects overall missed fewer targets per trial than subjects in the Sham $(p<0.01)$ and Cathodal $(p=0.03)$ groups. Moreover, when we looked at the average force distance error from each of the targets, we also found a significant effect for DAY $\left(F_{(2,60)}=7.40, p<\right.$ $0.01), \operatorname{BLOCK}\left(F_{(5,150)}=8.99, p<0.01\right), \operatorname{GROUP}\left(F_{(2,30)}=3.86\right.$, $p=0.03)$, and DAY $\times$ BLOCK interaction $\left(F_{(10,150)}=7.74, p<\right.$ $0.01)$. Here, anodal subjects showed significantly smaller peak force distance errors across each of the targets compared with subjects in the Sham group $(p<0.01)$. This indicates that the amplitude of the overshooting and undershooting movements 

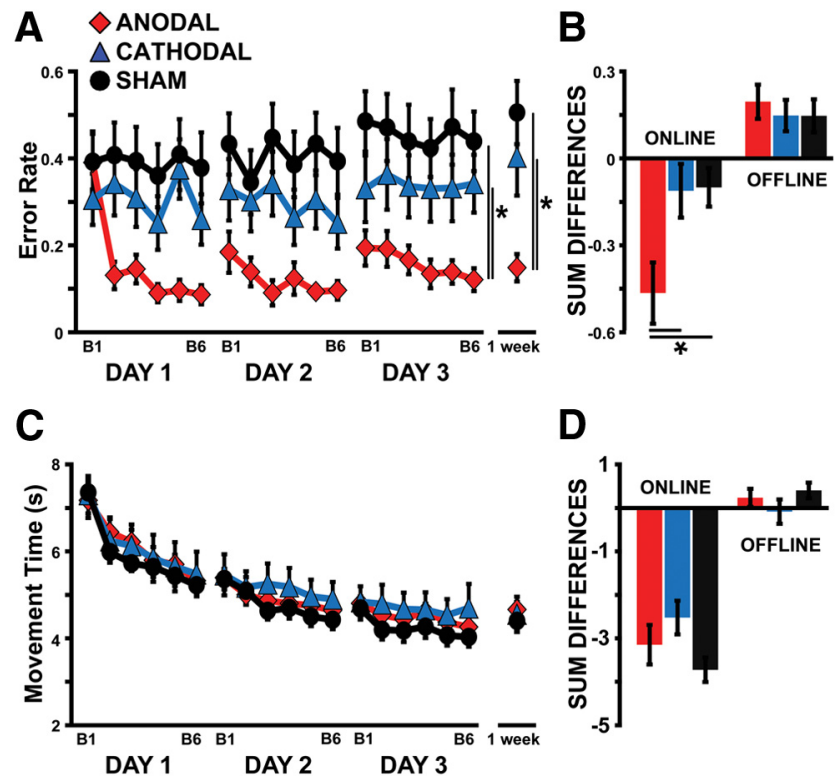

Figure 3. Error rate versus movement time. Red diamonds are the average performances of the Anodal group. Blue triangles represent the Cathodal group. Black circles denote the Sham group. $A, y$-axis represents the error rate and $x$-axis denotes training blocks across days. Despite all subjects having similar error-rate levels at the beginning of the study, those in the Anodal group improved their accuracy beyond the levels achieved by the subjects in the Cathodal and Sham groups. $\boldsymbol{B}$, The bar graph shows group averages of the error rate for the sum of on-line and off-line changes. Subjects with anodal stimulation showed larger improvements in on-line changes compared with Cathodal and Sham groups. C, $y$-axis represents movement time and the $x$-axis represents training blocks across days. All groups showed similar improvements in movement time across training blocks. $\boldsymbol{D}$, The bar graph shows group averages of movement time for the sum of on-line and off-line changes. All groups showed similar changes in on-line and off-line effects. Data are means \pm SEM. ${ }^{*} p \leq 0.05$.

when aiming at the different targets was smaller for the Anodal group relative to the Sham group. However, there was not a significant difference between anodal subjects compared with cathodal subjects $(p=0.22)$.

Similar to the skill measure, on-line effects in error rate were significantly different across the three groups $\left(F_{(2,32)}=5.34, p=\right.$ $0.01)$. Namely, subjects in the Anodal tDCS group showed significantly larger on-line reductions in error rate over the course of training compared with subjects in the Sham $(p<0.01)$ and Cathodal groups $(p<0.01$; Fig. $3 B)$. In addition, when comparing total gains across groups, the Anodal tDCS group $\left(F_{(2,31)}=\right.$ 7.17, $p<0.01)$ exhibited significantly greater overall learning compared with both the Sham $(p<0.01)$ and Cathodal tDCS $(p<0.01)$ groups, while there was no significant difference between Sham and Cathodal groups $(p=0.91)$. There was no significant difference across groups for off-line effects $\left(F_{(2,32)}=\right.$ $0.24, p=0.79$ ).

On the other hand, although there were significant differences in movement time for DAY $\left(F_{(2,60)}=173.41, p<0.01\right)$, BLOCK $\left(F_{(5,150)}=106.76, p<0.01\right)$, and a DAY $\times$ BLOCK interaction $\left(F_{(10,300)}=21.20, p<0.01\right)$, there were no significant differences between GROUPS $\left(F_{(2,30)}=0.35, p=0.71\right.$; Fig. $\left.3 C\right)$. Nor were there any significant differences in on-line $\left(F_{(2,32)}=2.44, p=\right.$ $0.11)$ and off-line effects $\left(F_{(2,32)}=1.18, p=0.32\right)$, in long-term retention $\left(F_{(2,32)}=0.20, p=0.82\right)$, or in total gains $\left(F_{(2,32)}=\right.$ $1.28, p=0.29$; Fig. $3 D)$. This indicates that all groups showed similar improvements in speed.

Altogether these results indicate that although subjects in the Anodal group improved in both accuracy and movement time, the overall performance difference in skill learning between the groups was largely driven by differences in accuracy with subjects in the Anodal group making overall fewer errors during training.

\section{Discussion}

Anodal ctDCS increased overall skill acquisition relative to sham and cathodal ctDCS. In contrast to M1 tDCS, the beneficial effects of anodal ctDCS relied on larger on-line rather than off-line gains. Moreover, the larger skill improvement in the anodal group was predominantly mediated by reductions in error rate rather than movement time.

In motor learning, plastic changes occur in both M1 (Karni et al., 1995; Pascual-Leone et al., 1995; Kleim et al., 1998b; Rosenkranz et al., 2007; Cantarero et al., 2013a) and the cerebellum (Anderson et al., 1996; Kleim et al., 1998a; Schlerf et al., 2012), leading to acquisition and consolidation of new motor memories. In particular, the cerebellum has been implicated as playing a role in motor adaptation tasks. Learning this type of behavior relies in part, but not exclusively, on error-dependent-learning mechanisms (Huang et al., 2011), which allow performance to return to baseline levels in the context of perturbations. This process occurs on a timescale of minutes to hours by correcting prediction errors (Bastian, 2008).

Similarly in motor adaptation task studies (Galea et al., 2011; Jayaram et al., 2012; Herzfeld et al., 2014), we found that anodal ctDCS applied during motor-skill training also improved learning, indicating that the cerebellum is relevant in both adaptation and skill tasks. Our results suggest that error-base-learning, thought to be cerebellar dependent, may be a relevant learning mechanism that also underlies the acquisition of skill tasks. However, an alternative interpretation is that the cerebellum is also involved in other mechanisms of learning, such as reinforcement driven by reward, traditionally thought to be mediated by basal ganglia connections to M1 (Taylor and Ivry, 2014; Ullsperger et al., 2014), or strategic learning via the modulation of prefrontal areas responsible for cognitive strategies and working memory (Stoodley, 2012).

Cathodal ctDCS, an intervention shown to decrease cerebellar excitability (Galea et al., 2009), did not affect motor behavior. One might expect cathodal stimulation to impair motor learning since it's been shown in a force field adaptation task to affect error sensitivity (Herzfeld et al., 2014). However, the lack of effect is consistent with other studies applying cathodal-M1 tDCS during skill training (Nitsche et al., 2003b; Reis et al., 2009). This negative finding highlights the issue that the mechanisms of tDCS remain unclear and may suggest that cathodal stimulation was not strong enough to interfere with cerebellar processes, is not necessarily the behavioral inverse of anodal stimulation, or may not be exclusively affecting the cerebellum (for review, see Grimaldi et al., 2014). However, a recent modeling paper that predicted both the strength and direction of the electric fields of the most commonly used tDCS configurations (i.e., M1, dorsolateral prefrontal cortex, inferior frontal gyrus, occipital cortex, and cerebellum) showed that the configuration montage for the cerebellum (as used in this study) was the most accurate and effective at targeting the intended area (Rampersad et al., 2014). Nonetheless, given the similar sensations elicited by cathodal ctDCS, this group is an optimal control to rule out nonspecific effects of anodal ctDCS. 


\section{On-line versus off-line changes}

Unlike previous research testing single-session ctDCS effects, we studied these effects over several days to assess the relative contribution of on-line and off-line changes on overall learning. We found that larger learning at the end of $3 \mathrm{~d}$ of practice in the Anodal group was mediated by larger on-line gains. Interestingly, the Anodal group also had larger off-line losses between training sessions. However, the percentage decrement in off-line changes was no different across groups. Because anodal subjects reach a higher level of performance at the end of each practice session, they have more to lose in absolute terms. However, the magnitude of retention was not different between groups. This explains why total learning was still better in the Anodal group. Alternatively, it's possible that there's a maximum that can be retained from a session; hence, despite better performance at the end of the day, not all additional gains are stored.

Previously, we've shown larger total learning when anodal M1 tDCS was applied during skill training of the same task (Reis et al., 2009). However, that study showed the beneficial effect of M1 anodal tDCS was driven primarily by enhanced off-line rather than on-line gains (Reis et al., 2009). In other words, M1 tDCS improved overall learning by increasing retention across days. Importantly, these results are congruent with other human studies showing that disruptive TMS over M1 impaired retention but not acquisition of motor learning (Muellbacher et al., 2002; Robertson et al., 2004, 2005; Richardson et al., 2006; HadipourNiktarash et al., 2007). This dichotomy in the roles of the cerebellum and M1 in motor learning is consistent with another study showing that anodal ctDCS increased the acquisition rate without affecting its retention and that anodal M1 tDCS modulated the amount of retention without affecting acquisition of an adaptation task (Galea et al., 2011). Thus, our results together with those of prior studies support the notion that the cerebellum is critically involved in the acquisition of motor learning, whereas M1 is involved in the retention of motor learning.

\section{Movement time versus error rate}

Motor tasks contain two main components: speed (i.e., movement time) and accuracy (i.e., error rate; Fitts, 1954). Recently skill learning has been operationalized as changes in the speed-accuracy tradeoff function to avoid falsely identifying improvements in speed while accuracy worsens (or vice versa) as learning (Reis et al., 2009). For our task, we have developed a measure that accounts for changes in both components to assess true skill learning.

Using the skill measure, we found that anodal ctDCS increased total learning via on-line changes. However, to better understand the role of the cerebellum during skill learning, we also analyzed whether the overall improvement was mediated by changes in accuracy or speed. We hypothesized that given the cerebellum's role in forming internal models that predict the consequences of movements (error-base-learning mechanisms), increasing its excitability during skill training would help reduce errors. By allowing both parameters to change freely during training, we could determine which component of learning, speed or accuracy, was more affected by ctDCS. We found that the larger skill improvement in the Anodal group was predominantly mediated by larger reductions in error rate rather than movement time. This is consistent in part with motor adaptation studies where anodal ctDCS improved adaptation specifically by decreasing movement errors without affecting the speed of movements (Galea et al., 2011; Jayaram et al., 2012), albeit these studies constrained movement time to perform the task. Overall, our findings suggest that different components of motor-skill learning (i.e., error and speed) may be predominantly controlled by different neural circuits with the cerebellum largely influencing error reduction.

Although not directly addressed in the current design, a potential mechanism for the effects found here is that by increasing cerebellar excitability, sensitivity to motor-error signals improves, resulting in better trial-to-trial learning. Alternatively, it's possible that the on-line changes observed are not due to direct cerebellar modulation, but rather facilitation of distant structures connected to the cerebellum (i.e., prefrontal cortex). We think this possibility is unlikely given that we found facilitation with anodal ctDCS, thought to increase cerebellar cortex excitability, resulting in more inhibition of the deep cerebellar nuclei (DCNs) and consequently of distant areas (Galea et al., 2009). A recent study found that cathodal ctDCS resulted in better performance of working memory tasks thought to depend on the dorsal lateral prefrontal cortex. This effect was interpreted as decreased excitability of the cerebellar cortex-released DCN inhibition with the subsequent facilitation of prefrontal areas (Pope and Miall, 2012).

In $\mathrm{M} 1$, anodal tDCS increases excitability via NMDA receptors, GABA, BDNF, and calcium-dependent mechanisms (Liebetanz et al., 2002; Nitsche et al., 2003a; Stagg et al., 2009) and induction of LTP in mice slice preparations (Fritsch et al., 2010). However, it's unknown whether these mechanisms also underlie increased cerebellar excitability and improvement in behavior observed with anodal ctDCS. Importantly though, ctDCS has been shown to affect cerebellar-M1 connectivity (Galea et al., 2009) and behavior in adaptation paradigms (Block and Celnik, 2013; Hardwick and Celnik, 2014).

\section{Implications}

This study suggests that ctDCS can facilitate motor skill learning. Since anodal tDCS allows subjects to acquire motor skills faster, this intervention could reduce the time needed to train patients with neurological conditions and speed up rehabilitation. However, there are important caveats to consider when thinking of translating this intervention to the clinical setting. First, the present motor task is a reductionist approach to assess skill learning. Thus, future studies should explore whether the observed benefits also transfer to more clinically relevant behaviors. Second, our results show some variability in responsiveness to the benefits of stimulation across individuals. Future studies will need to consider investigating the sources of interindividual responsiveness to brain stimulation to help identify candidates who are more likely to benefit from the application of cerebellar stimulation, as well as shape stimulation parameters to optimize behavioral effects.

Another important consideration is whether we can selectively enhance different components of motor learning by stimulating different brain regions. Depending on the task, we could apply anodal tDCS over the cerebellum to improve accuracy and on-line learning. Perhaps even more exciting is to possibly apply simultaneous M1 and cerebellar stimulation to maximize improvements in motor training by affecting both on-line and offline learning.

\section{References}

Anderson BJ, Alcantara AA, Greenough WT (1996) Motor-skill learning: changes in synaptic organization of the rat cerebellar cortex. Neurobiol Learn Mem 66:221-229. CrossRef Medline

Bastian AJ (2008) Understanding sensorimotor adaptation and learning for rehabilitation. Curr Opin Neurol 21:628-633. CrossRef Medline

Black JE, Isaacs KR, Anderson BJ, Alcantara AA, Greenough WT (1990) Learning causes synaptogenesis, whereas motor activity causes angiogen- 
esis, in cerebellar cortex of adult rats. Proc Natl Acad Sci U S A 87:55685572. Medline

Block H, Celnik P (2013) Stimulating the cerebellum affects visuomotor adaptation but not intermanual transfer of learning. Cerebellum 12:781793. CrossRef Medline

Cantarero G, Tang B, O’Malley R, Salas R, Celnik P (2013a) Motor learning interference is proportional to occlusion of LTP-like plasticity. J Neurosci 33:4634-4641. CrossRef Medline

Cantarero G, Lloyd A, Celnik P (2013b) Reversal of long-term potentiationlike plasticity processes after motor learning disrupts skill retention. J Neurosci 33:12862-12869. CrossRef Medline

Dayan E, Cohen LG (2011) Neuroplasticity subserving motor skill learning. Neuron 72:443-454. CrossRef Medline

Diedrichsen J, Hashambhoy Y, Rane T, Shadmehr R (2005) Neural correlates of reach errors. J Neurosci 25:9919-9931. CrossRef Medline

Donchin O, Rabe K, Diedrichsen J, Lally N, Schoch B, Gizewski ER, Timmann D (2012) Cerebellar regions involved in adaptation to force field and visuomotor perturbation. J Neurophysiol 107:134-147. CrossRef Medline

Fitts PM (1954) The information capacity of the human motor system in controlling the amplitude of movement. J Exp Psychol 47:381-391. CrossRef Medline

Fritsch B, Reis J, Martinowich K, Schambra HM, Ji Y, Cohen LG, Lu B (2010) Direct current stimulation promotes BDNF-dependent synaptic plasticity: potential implications for motor learning. Neuron 66:198-204. CrossRef Medline

Galea JM, Celnik P (2009) Brain polarization enhances the formation and retention of motor memories. J Neurophysiol 102:294-301. CrossRef Medline

Galea JM, Jayaram G, Ajagbe L, Celnik P (2009) Modulation of cerebellar excitability by polarity-specific noninvasive direct current stimulation. J Neurosci 29:9115-9122. CrossRef Medline

Galea JM, Vazquez A, Pasricha N, de Xivry JJ, and Celnik P (2011) Dissociating the roles of the cerebellum and motor cortex during adaptive learning: the motor cortex retains what the cerebellum learns. Cereb Cortex 21:1761-1770. CrossRef Medline

Grimaldi G, Argyropoulos GP, Bastian A, Cortes M, Davis NJ, Edwards DJ, Ferrucci R, Fregni F, Galea JM, Hamada M, Manto M, Miall RC, MoralesQuezada L, Pope PA, Priori A, Rothwell J, Tomlinson SP, Celnik P (2014) Cerebellar transcranial direct current stimulation (ctDCS): a novel approach to understanding cerebellar function in health and disease. Neuroscientist pii:1073858414559409. Medline

Hadipour-Niktarash A, Lee CK, Desmond JE, Shadmehr R (2007) Impairment of retention but not acquisition of a visuomotor skill through timedependent disruption of primary motor cortex. J Neurosci 27:13413-13419. CrossRef Medline

Hardwick RM, Celnik PA (2014) Cerebellar direct current stimulation enhances motor learning in older adults. Neurobiol Aging 35:2217-2221. CrossRef Medline

Herzfeld DJ, Pastor D, Haith AM, Rossetti Y, Shadmehr R, O'Shea J (2014) Contributions of the cerebellum and the motor cortex to acquisition and retention of motor memories. Neuroimage 98:147-158. CrossRef Medline

Huang VS, Haith A, Mazzoni P, Krakauer JW (2011) Rethinking motor learning and savings in adaptation paradigms: model-free memory for successful actions combines with internal models. Neuron 70:787-801. CrossRef Medline

Islam N, Aftabuddin M, Moriwaki A, Hattori Y, Hori Y (1995) Increase in the calcium level following anodal polarization in the rat brain. Brain Res 684:206-208. CrossRef Medline

Jayaram G, Galea JM, Bastian AJ, Celnik P (2011) Human locomotor adaptive learning is proportional to depression of cerebellar excitability. Cereb Cortex 21:1901-1909. CrossRef Medline

Jayaram G, Tang B, Pallegadda R, Vasudevan EV, Celnik P, Bastian A (2012) Modulating locomotor adaptation with cerebellar stimulation. J Neurophysiol 107:2950-2957. CrossRef Medline

Karni A, Meyer G, Jezzard P, Adams MM, Turner R, Ungerleider LG (1995) Functional MRI evidence for adult motor cortex plasticity during motor skill learning. Nature 377:155-158. CrossRef Medline

Kleim JA, Swain RA, Armstrong KA, Napper RM, Jones TA, Greenough WT (1998a) Selective synaptic plasticity within the cerebellar cortex following complex motor skill learning. Neurobiol Learn Mem 69:274-289. CrossRef Medline
Kleim JA, Barbay S, Nudo RJ (1998b) Functional reorganization of the rat motor cortex following motor skill learning. J Neurophysiol 80:33213325. Medline

Kleim JA, Freeman JH Jr, Bruneau R, Nolan BC, Cooper NR, Zook A, Walters D (2002) Synapse formation is associated with memory storage in the cerebellum. Proc Natl Acad Sci U S A 99:13228-13231. CrossRef Medline

Krakauer JW, Mazzoni P (2011) Human sensorimotor learning: adaptation, skill, and beyond. Curr Opin Neurobiol 21:636-644. CrossRef Medline

Liebetanz D, Nitsche MA, Tergau F, Paulus W (2002) Pharmacological approach to the mechanisms of transcranial DC-stimulation-induced aftereffects of human motor cortex excitability. Brain 125:2238-2247. CrossRef Medline

Martin TA, Keating JG, Goodkin HP, Bastian AJ, Thach WT (1996) Throwing while looking through prisms. I. Focal olivocerebellar lesions impair adaptation. Brain 119:1183-1198. CrossRef Medline

Muellbacher W, Ziemann U, Wissel J, Dang N, Kofler M, Facchini S, Boroojerdi B, Poewe W, Hallett M (2002) Early consolidation in human primary motor cortex. Nature 415:640-644. CrossRef Medline

Nitsche MA, Schauenburg A, Lang N, Liebetanz D, Exner C, Paulus W, Tergau F (2003a) Facilitation of implicit motor learning by weak transcranial direct current stimulation of the primary motor cortex in the human. J Cogn Neurosci 15:619-626. CrossRef Medline

Nitsche MA, Fricke K, Henschke U, Schlitterlau A, Liebetanz D, Lang N, Henning S, Tergau F, Paulus W (2003b) Pharmacological modulation of cortical excitability shifts induced by transcranial direct current stimulation in humans. J Physiol 553:293-301. CrossRef Medline

Pascual-Leone A, Nguyet D, Cohen LG, Brasil-Neto JP, Cammarota A, Hallett M (1995) Modulation of muscle responses evoked by transcranial magnetic stimulation during the acquisition of new fine motor skills. J Neurophysiol 74:1037-1045. Medline

Pope PA, Miall RC (2012) Task-specific facilitation of cognition by cathodal transcranial direct current stimulation of the cerebellum. Brain Stimul 5:84-94. CrossRef Medline

Rampersad SM, Janssen AM, Lucka F, Aydin Ü, Lanfer B, Lew S, Wolters CH, Stegeman DF, Oostendorp TF (2014) Simulating transcranial direct current stimulation with a detailed anisotropic human head model. IEEE Trans Neural Syst Rehabil Eng 22:441-452. CrossRef Medline

Reis J, Schambra HM, Cohen LG, Buch ER, Fritsch B, Zarahn E, Celnik PA, Krakauer JW (2009) Noninvasive cortical stimulation enhances motor skill acquisition over multiple days through an effect on consolidation. Proc Natl Acad Sci U S A 106:1590-1595. CrossRef Medline

Richardson AG, Overduin SA, Valero-Cabré A., Padoa-Schioppa C, PascualLeone A, Bizzi E, Press DZ (2006) Disruption of primary motor cortex before learning impairs memory of movement dynamics. J Neurosci 26 : 12466-12470. CrossRef Medline

Robertson EM, Pascual-Leone A, Miall RC (2004) Current concepts in procedural consolidation. Nat Rev Neurosci 5:576-582. CrossRef Medline

Robertson EM, Press DZ, Pascual-Leone A (2005) Off-line learning and the primary motor cortex. J Neurosci 25:6372-6378. CrossRef Medline

Rosenkranz K, Kacar A, Rothwell JC (2007) Differential modulation of motor cortical plasticity and excitability in early and late phases of human motor learning. J Neurosci 27:12058-12066. CrossRef Medline

Schlerf JE, Galea JM, Bastian AJ, Celnik PA (2012) Dynamic modulation of cerebellar excitability for abrupt, but not gradual, visuomotor adaptation. J Neurosci 32:11610-11617. CrossRef Medline

Smith MA, Shadmehr R (2005) Intact ability to learn internal models of arm dynamics in Huntington's disease but not cerebellar degeneration. J Neurophysiol 93:2809-2821. CrossRef Medline

Stagg CJ, Best JG, Stephenson MC, O’Shea J, Wylezinska M, Kincses ZT, Morris PG, Matthews PM, Johansen-Berg H (2009) Polarity-sensitive modulation of cortical neurotransmitters by transcranial stimulation. J Neurosci 29:5202-5206. CrossRef Medline

Stoodley CJ (2012) The cerebellum and cognition: evidence from functional imaging studies. Cerebellum 11:352-365. CrossRef Medline

Taylor JA, Ivry RB (2014) Cerebellar and prefrontal cortex contributions to adaptation, strategies, and reinforcement learning. Prog Brain Res 210: 217-253. CrossRef Medline

Ullsperger M, Danielmeier C, Jocham G (2014) Neurophysiology of performance monitoring and adaptive behavior. Physiol Rev 94:35-79. CrossRef Medline 